\title{
Report on the First Liberia Conference in Bremen, October 1986
}

\author{
Von Veronika Fuest
}

On October 4th and 5th last year, a motley congegration met in Germany's most famous "Úbersee-Museum" to attend a conference organized by a Germany-based association called the Liberia Working Group. Both international participation and the fact that many specialists on Liberia convened in Germany for the first time - in a country that has little historical background for such ventures - promised to make it an interesting event. The surprisingly large number of 45 participants comprised development experts, academic scientists, students, and representatives of German companies in Liberia. A quarter of the assembly were foreign guests, including some prominent visitors from overseas. Among the Liberian participants, who live in exile in Germany or Holland, the most widely known was Dr. Togba-Nah Tipoteh, the former Minister of Planning and Economic Affairs.

Most of the lectures and discussions were held in English and were of remarkable depth. They covered a wider rariety of topices than the motto of the conference had suggested: "Liberia's political and economic future after the elections and the coup attempt in 1985“. The topics ranged from global macro-economical development issues (Prof. Dr. Karl Wohlgemuth) to specific methodical problems of atlas mapping in Liberia (Prof. Dr. William R. Stanley). Other contributions referred to Liberia's monetary problems (Prof. Dr. G. Völker; Dr. Claudia Dziobek), economic developments (Prof. Dr. Tipoteh), the military regime (Dr. Robert Kappel), and the role of the churches and of student resistance in political change (Dr. Werner Korte and Dr. Stephen S. Hlophe resp.). Lectures about deforestation (Prof. Dr. Karl-Heinz Hasselmann) and the iron ore sector (Dr. Kappel) illustrated the damage done to the country as a result of uncontrolled exploitation of resources by foreign companies. The question why basic foodstuffs have to be imported in spite of Liberia's vast agricultural potential was raised by two contributions on food production and supply (Siapha Kamara; Christina Salonek). More strictly development-related topics were treated in papers about German development cooperation (Dr. Helmut Großkreutz), women's programs (Veronika Fuest), and the health care system in Liberia (Dr. Norbert Remmert). The ensuing discussions, which focussed on development issues and the present political situation in Liberia, were very animated and partly controversial.

While most of the speakers gave general overviews of Liberian political, economic and development problems, there were only a few case studies giving insights below the macro-level. Analyses of constraints in changing local systems of food production and nutrition and of the neglect of women's economic roles in development projects sounded a warning against the fallacies technocrats may commit in development planning. Critic- 
isms of external dependence in most development sectors, to an extreme degree in the national health system, provided the background for questions concerning the possibilities of truly self-reliant development under present political conditions and of the utilisation of indigenous know-how as a starting point of development at the grassroots level. There was general agreement that development efforts would only succeed as part of a comprehensive economic and political re-orientation. In the face of Liberia's present power structure and the support of the system by the USA, there is little hope that the country will enter the path to democracy and economic equality in the foreseeable future.

A conference reader containing most of the presentations can be obtained from: Liberia Working Group, Grubenbacherstraße 40, D - 6315 Mücke, Federal Republic of Germany. 